\title{
The Impact of Computer-Mediated Communication Environments on Foreign Language Learning: A Review of the Literature
}

\author{
Hassan Saleh Mahdi ${ }^{1, *}$ \\ ${ }^{1}$ College of Arts and Science, Najran University, Najran, Saudi Arabia \\ *Correspondence: College of Arts and Science, Najran University, Najran, Saudi Arabia. Tel: 966-553-640-063 \\ E-mail: almatari7@gmail.com
}

Received: November 1, 2013 Accepted: January 3, $2014 \quad$ Online Published: February 17, 2014

doi:10.5430/wjel.v4n1p9 URL: http://dx.doi.org/10.5430/wjel.v4n1p9

\begin{abstract}
This article reviews the literature on the implementation of computer-mediated communication (CMC) in language learning. This review aims at understanding how CMC environments have been implemented to foster language learning. The review draws on 40 recent research articles selected form 10 peer-reviewed journals, 2 book chapters and one conference proceeding. This review investigates the studies that have dealt with the CMC environments used for language learning. It reviews the studies that have explored the benefits of CMC in language learning; factors affecting the use of CMC in language learning, and current CMC environments used for language learning (such as emails, wikis, YouTube, Facebook). Only peer-reviewed articles have been selected. The review discusses the findings of these studies and suggests guidelines for future research studies in this area. It concluded that further studies are necessary to investigate how language teachers can integrate CMC environments and organize suitable tasks. Also, further studies are necessary to determine the principles that are required to implement CMC in language learning.
\end{abstract}

Keywords: Computer-Mediated Communication (CMC); benefits of CMC; factors affecting CMC; language skills; CMC environments

\section{Introduction}

Computer-mediated communication (hereafter CMC) is a popular environment that has changed the way of our daily life, work, and learning. It helps us to communicate with people all around the world. CMC activities can be asynchronous, i.e. in the form of writing emails, or posting responses to a discussion board online, or can be virtual synchronous conversations held in chat rooms, and so on. The developments of computer technology have created new opportunities for language learning that cannot be found in traditional classrooms. Many environments have been introduced to enhance language learning. One of these is computer-mediated communication. CMC can be broadly defined as "human communication via computer" (Higgins, 1991). It involves interaction between humans using computers to connect to each other and generally refers to "any communication pattern mediated through the computer" (Metz, 1994). Many studies and books have been published about the uses of CMC in language learning. They have discussed a wide range of topics such as the benefits of CMC in comparison to traditional classrooms, CMC environments used for language learning and the factors affecting the uses of CMC in language learning. These studies need to be reviewed to help the researchers find out the area that were not explored or not fully examined. Therefore, the present review tries to shed the light on the areas that require more attention. The purpose of this review is to answer the following questions:

1. What are the general factors affecting the implementation of CMC in language learning?

2. What are the uses of CMC in teaching language skills?

3. What are the current CMC environments used for language learning? 


\section{Reviewing the Related Literature}

The implementation of CMC in language learning has been examined by many journal articles, conference proceedings, and books. Some attempts were introduced to review these studies. Cole, Beam, Karn and Hoad-Reddick (1992) listed more than 400 references regarding CMC, but only about 15\% of them were empirical studies. Wallace (2003) reviewed more research articles to examine the interaction among teachers and students in higher education. Romiszowski and Mason (2004) reviewed over 100 articles published between 1996 and 2003. They focused on the current growth in research on asynchronous text-based CMC. Luppicini (2007) reviewed 170 research articles chosen from 78 journals to examine the recent developments in CMC research for educational environments. The major limitation of these reviews is that they have examined the uses of CMC in general education, not language learning. Lin, Huang and Lion (2013) examined the degree of the effect of text-based synchronous computer-mediated communication (SCMC) on second language acquisition (SLA). Ten experimental and quasi-experimental articles and doctoral dissertations published between 1990 and 2012 were analyzed. Abraham (2008) analyzed 11 studies of computer-mediated glosses in second language reading comprehension and incidental vocabulary learning. He supposed that computer-mediated glosses had a medium effect on second language reading comprehension and a large effect on incidental vocabulary learning. He found that mean effect sizes varied from medium to large depending upon the level of instruction, text type, and assessment tasks.

In general, the literature paid less attention to the principles that are necessary to implement CMC in language learning. Therefore, a comprehensive review of research studies on the implementation of CMC in language learning is needed. The present review tries to fill in this gap in the knowledge regarding the current state of CMC in language learning.

Table 1. Reviews of the Studies in CMC

\begin{tabular}{lllll}
\hline Reviewer & Objectives & Period & $\begin{array}{l}\text { No. of } \\
\text { articles }\end{array}$ & Main findings \\
\hline $\begin{array}{l}\text { Wallace } \\
\text { (2003) }\end{array}$ & $\begin{array}{l}\text { to examine the interaction among } \\
\text { teachers and students in higher } \\
\text { education }\end{array}$ & $\begin{array}{l}\text { No date } \\
\text { specified }\end{array}$ & 100 & $\begin{array}{l}\text { Little work done to examine the relationship } \\
\text { between social interaction and learning }\end{array}$ \\
$\begin{array}{l}\text { Luppicini } \\
\text { (2007) }\end{array}$ & $\begin{array}{l}\text { to examine the recent } \\
\text { developments in CMC research for } \\
\text { educational environments }\end{array}$ & $\begin{array}{l}\text { No date } \\
\text { specified }\end{array}$ & 170 & $\begin{array}{l}\text { Partial advantages of CMC in writing, task } \\
\text { focused discussion, collaborative } \\
\text { decision-making, group work, and active } \\
\text { involvement in knowledge construction during } \\
\text { group interactions. }\end{array}$ \\
$\begin{array}{l}\text { Lin, } \\
\begin{array}{l}\text { Huang } \\
\text { and Lion } \\
\text { (2013) }\end{array}\end{array}$ & $\begin{array}{l}\text { To explore the degree of the effect } \\
\text { of text-based synchronous } \\
\text { computer-mediated } \\
\text { communication (SCMC) on } \\
\text { second language acquisition }\end{array}$ & 1990 and & 10 & $\begin{array}{l}\text { Text-based SCMC could make a larger } \\
\text { difference on SLA than other ways of } \\
\text { communication. Also, the learners may benefit } \\
\text { more from SCMC tasks if they are grouped into } \\
\text { pairs or small groups and participate in SCMC } \\
\text { interactions on a weekly basis. }\end{array}$ \\
$\begin{array}{llll}\text { Abraham } \\
\text { (2008) }\end{array}$ & $\begin{array}{l}\text { To examine computer-mediated } \\
\text { glosses had an overall medium } \\
\text { effect on second language reading } \\
\text { comprehension and a large effect } \\
\text { on incidental vocabulary learning }\end{array}$ & $\begin{array}{l}\text { No date } \\
\text { specified }\end{array}$ & 11 & $\begin{array}{l}\text { The mean effect sizes varied from medium to } \\
\text { large depending upon the level of instruction, } \\
\text { text type, and assessment tasks. }\end{array}$ \\
\hline
\end{tabular}

\section{Methodology}

This review has employed several procedures in the collection and analysis of articles related to CMC implementation in language learning. First, a key word search using "computer-mediated communication", "computer-mediated communication environments for language learning", and "online communication and language learning” was performed in Education Resources Information Centre (ERIC), SCOPUS, EBSCO and Proquest online databases. For the key words, around 100 articles were found. The results of these studies were carefully checked. Then 40 studies were selected for the review since they matched the key words of this article and covered CMC for 
language learning. The criteria for selecting these studies are:

1. Only peer-reviewed studies were included.

2. The objective of these studies is language learning, not general education.

3. Only empirical studies were included.

4. No date restriction.

5. Doctoral dissertations, master's thesis, unpublished technical reports, non-refereed articles and abstracts were not included.

The selected studies were published in 10 journals, 2 book chapters and one conference proceeding.

Table 2. Journal Titles and Number of Studies

\begin{tabular}{ll}
\hline Title of journal & No. of articles \\
\hline Computer Assisted Language Learning & 10 \\
ReCALL & 9 \\
Language Learning \& Technology & 6 \\
CALICO & 4 \\
System & 2 \\
Australasian Journal of Educational Technology & 2 \\
Journal of Computer Assisted Learning & 1 \\
American Journal of Distance Education & 1 \\
Foreign Language Annuals & 1 \\
E-Learning and Digital Media & 1 \\
Proceedings of world conference on educational multimedia, hypermedia and telecommunications & 1 \\
\hline
\end{tabular}

\section{Results and Discussion}

The studies of CMC implementation in language learning can be classified under the following categories.

\subsection{Benefits of CMC for Language Learning}

This section summarizes the benefits of CMC in language learning as examined by the selected research articles in this review. Warschauer (2001) pointed out that the participation in CMC is more balanced than in the face-to-face interaction which is dominated by some students. Also, Barrs (2012) investigated the impact of CMC on learners' interaction to develop target language interaction outside the classroom. The results indicated that CMC environment can offer students a suitable and useful platform on which to continue to communicate in the target language while outside of their classes. Blake (2000) analyzed the discourse created in the chat windows to find out if they had a significant effect on language learning. The study found that CMC can provide many benefits and increased possibilities for access outside of the classroom environment. Similarly, Zeng and Takatuska (2009) examined EFL learner's dialogues in synchronous task-based CMC. They found that CMC environments assisted learners' text-based collaborative dialogue and fostered their language learning. Pellettieri (2000) examined the effect of task-based network-based communication (NBC) to facilitate the negotiation of meaning and form-focused interaction. The study concluded that task-based synchronous NBC, such as chatting, can indeed foster the negotiation of meaning. Learners involved in NBC chats negotiate overall aspects of the discourse. CMC creates new opportunities for language learners to interact with each others. Wang (2006) found that videoconferencing-supported negotiation of meaning may facilitate second language acquisition at a distance and has its own distinct features. Young (2003) assumed that CMC would make learning English more socially interactive and reduce students' affective filters. The use of the internet appeared to motivate students and reduce their anxiety over language production. Freiermuth (2001) assumed that the students felt more comfortable in an online chat. They were less anxious about any language lacks that might cause them to refrain from speaking in a face-to-face setting. Kitade (2000) explored to what extent CMC actually a useful device for L2 was learning. The results indicated that CMC provides potential benefits for learning: facilitating comprehensible and contextualized interaction, learners' self-correction, and collaborative learning environment. Xiao and Yang (2005) pointed out that students in an EFL 
setting never have enough English native speakers to practice their English. Their solution was the use of web conferences which can offer EFL students the chance for interaction with native speakers of English. The results of this study found that CMC involving native speaking students was superior to face-to-face interaction with nonnative peers in two regards: significantly improved fluency for the experimental group, and, to a lesser degree, improved accuracy. This study demonstrated that CMC offers superior chances for interaction and improvement to students in an EFL setting where native speakers are few.

In sum, CMC is a useful environment for language learning. It facilitates the interaction between the teacher and the students, and also between the students themselves. It fosters the negotiation of meaning. The students feel comfortable when CMC is used. With the help of CMC, language learners can interact with native speakers of the target language easily at anytime and anywhere.

\subsection{Factors Affecting CMC}

It is not enough to apply CMC in language learning and wish its success. There are many factors to be considered to assure the success of CMC implementation in language learning. The context, modes, and task type are some of these factors. The methodology used for language learning also determines the success or failure of CMC. The teachers and learners' perceptions of CMC are essential issues to be considered. The technology itself, linguistic features, curriculum, and social affairs are also important factors to determine the success of CMC. The factors that have been examined by the previous studies can be studied under the following categories: the modes of CMC, task types, students' perceptions of CMC and social presence.

\subsubsection{Modes of CMC}

The modes of CMC (i.e., text, audio or video) have an influence on the ways language is learnt. Some research studies were conducted to explore the impact of CMC mode on language learning. Yanguas (2010) examined how learners in video and audio CMC group negotiate for meaning during task-based interaction. The participants of the study were randomly assigned to one of the three groups: video-conferencing, audio-conferencing, and face-to-face. The results revealed some differences in the way audio and video groups carry out the negotiations. However, the results showed no differences between video CMC and face-to-face groups. Video CMC interaction patterns were shown to be more versatile. Research studies on CMC have also investigated the impact of written CMC in comparison to oral CMC, and face-to-face classrooms. Sykes (2005) explored the strength of the connection between synchronous CMC and pragmatic instruction by measuring the effects of three types of synchronous group discussion (written chat, oral chat and traditional face-to-face). The study found that written chat groups outperformed the others in terms of both complexity and variety of strategies used.

\subsubsection{Task types}

The type of the task is also a crucial factor that affects the use of CMC. Brandl (2012) examined the effects of optional and required tasks on learners' quantity and quality of use the language. The results showed that optional task yielded significantly more learner output. However, students produced fewer errors when performing the required than optional tasks. Yilmaz and Granena (2010) examined the potential of learner-learner interaction through Synchronous Computer-Mediated Communication (SCMC) to focus learners' attention on form. The study compared two task types, jigsaw and dictogloss. The study showed that task type could affect learners' linguistic behavior. Yilmaz (2011) investigated if task type had any effect on the number and characteristics of focus-on-form on instances of English as a foreign language. Results showed that dictogloss task elicited a higher number of Language-related episodes (LREs) than the jigsaw task.

\subsubsection{Students' perceptions of CMC}

Students' perceptions and attitudes towards CMC can affect the implementation of CMC. Some studies have been conducted to examine this issue. Nguyen (2011) examined Vietnamese learners' reflections on and perceptions of the environment of computer-mediated communication (CMC) into collaborative learning. The majority of participants enjoyed the technology-enhanced class in general. There were approximately equal numbers of students who preferred synchronous CMC, asynchronous CMC, or a combination of both. The students reported that the course helped improve their computer skills and collaborative experience. More involvement in learning was observed during and after the course. In addition, the participants expressed confidence that they would attend similar courses in future and were willing to recommend this technology-embedded course to the next generations of students.

\subsubsection{Social Presence}

Social presence is another factor in determining the effectiveness of learning. It helps increase social interaction, 
encourage learning satisfaction, initiate in-depth discussions and promote collaborative learning. Social presence means the degree of feeling, perception and reaction of being connected on CMC to another intellectual entity (Tu, 2002). Therefore, the uses of CMC in language learning can be affected by the learners' perception of social presence in CMC. Ko (2012) investigated the impact of synchronous CMC learning environments on learners' perception of social presence. The participants of the study were divided into three groups: video/audio, audio, and face-to-face. The study found that the learners' perception of social presence was higher in the video/audio group and lower in audio group. Yamada and Akahori (2007) argued that social presence aids second language communication in learner-centered communication.

\subsection{CMC and Language Skills}

Language skills (i.e. listening, speaking, reading and writing) can be taught and learnt with the help of CMC. In the literature, many studies examined the impact of CMC on language skills. This section summarizes some of these studies.

\subsubsection{Listening}

O’Bryan ad Hegelheimer (2007) described a structured attempt to integrate the podcasts into English as a Second Language (ESL) course on listening strategies. Preliminary evaluation of this project suggested that both the teacher and the students found the podcasts to be a positive component of the course. Absalom and Rizzi (2008) described an initial exploratory study aimed at comparing the effects of online listening and online text-based tasks. They concluded that online listening tasks in L2 required students to activate more learning resources than is the case with text-based tasks and adopted a deep, integrative approach to learning. Also, online listening tasks in L2 could lead to greater retention of information and vocabulary and this greater retention of information and vocabulary can lead to noticeable cross modality gains. Listening group participants were better equipped to respond orally to questions about the content of the weekly tasks than text group participants.

\subsubsection{Speaking}

Speaking is one of the most important skills that language teachers and students concern about. Therefore, it received more attention in the literature. Alastuey (2011) explored the benefits and drawbacks of synchronous voice-based CMC in a blended course of English for specific purposes. The results showed that achievements were significantly better in the experimental group and that there was also an increase of other positive factors which may effectively contribute both to second language acquisition (SLA) and to solving many of the problems which make speaking skills the weakest skill in foreign language contexts. Shamsudin and Nesi (2006) examined the effectiveness of the chat feature of Windows NetMeeting as a tool for developing specified language skills. They found that students who used CMC ESP tasks made significant improvements in their oral communication skills, and also achieved higher scores than their peers in a computer science project undertaken in the semester following the treatment.

\subsubsection{Reading}

Fuente (2003) examined the differential effects of computer mediated interactions and face-to-face interactions in the acquisition of L2 word meanings by learners of Spanish. Receptive and productive, oral and written measures were used to assess acquisition and retention of the target items. The study suggested that computer mediated interaction tasks where negotiation of meaning took place clearly seem to be of great benefit to help learners advance in their L2 lexical development. Murphy (2010) examined (a) whether the introduction of computer-mediated feedback better promoted quality interaction and comprehension of a web-based reading text and (b) whether CMC offered a suitable means for generating quality interaction between peers in remote locations. The results from a qualitative analysis of interactions suggested that CMC is a suitable way of generating quality interaction between students.

\subsubsection{Writing}

Vurdien (2011) explored how a blog as a computer-mediated tool engaged a group of English as Foreign Language learners at a language school in Spain in reflective and collaborative learning. The activities focused on the specific writing tasks. The study found that the engagement in negotiation of meaning between peers led to better planning and the choice of the right register/style required in each task prior to writing and submitting their work. Collaborative skills were also fostered through students' regular interaction in the blogs. The study suggested that for meaningful learning to take place, pedagogical intervention could encourage students to take their peers' comments into account so that they can edit their own work with a view to enhancing their writing tasks and producing mistake-free texts. Shang (2007) examined the overall effect of using email on the improvement of writing performance in aspects of syntactic complexity, grammatical accuracy and lexical density, as well as investigating the relation between the number of email exchanges and writing performance. The major finding demonstrated that 
students made improvements on syntactic complexity and grammatical accuracy. Another finding suggested that exchanging email messages with their peers at least four times might have a greater overall improvement on their writing performance.

\subsection{The Current CMC Environments Applied for Language Learning}

Nowadays, many CMC environments are introduced. People can communicate via computer in many ways (i.e. written, audio and video). Skype, MSN, Facebook, YouTube, and Twitter are some examples of CMC environments used for communication by a large number of people around the world. These environments can be applied in the field of language teaching and learning. The integration of these environments creates new opportunities for language teachers and learners to be in contact even if they are out of the classrooms.

Technically, each environment has its own unique features which can create something different from other environments. This section deals with different environments of CMC and their environments in language teaching and learning. It reviews the previous studies that examined how these environments were applied in language teaching and learning.

\subsubsection{Skype}

Skype is an internet service that provides audio and video chatting windows. Users can set up conference calls with many people at the same time. Skype is a useful tool for language learning. Robert (2005) found that Skype offers fascinating opportunities for language professionals and learners, as they provide additional channels for oral communication. Skype is also an effective tool for language teachers. Suk, Young and Vrongistinos (2012) examined the nature of the Blackboard and Skype-based electronic mentoring system for beginning teachers. They found that the data analysis indicated that the combination of using Blackboard and Skype tools was beneficial to beginning teachers' effective teaching of English language learners. Develotte, Guichon and Vincent (2010) explored how language teachers learn to teach with a synchronous multimodal setup "Skype" and it focused on their use of the webcam during the pedagogical interaction. The study presented five degrees of webcam utilization (i.e. from non-utilization to full use of webcam). The study suggested that the last degree (full use of webcam) allowed for an intense interaction and augmented the feeling of co-presence. Yanguas (2010) examined how learners in video and audio CMC group negotiate for meaning during task-based interaction using Skype as a tool to carry out the study. Skype was used by students to carry their conversations in the computer lab. The results indicated that using Skype for the oral CMC group created turn-taking patterns that were very close to face-to-face turn-taking.

\subsubsection{Facebook}

Facebook is a social networking service launched in February 2004. Facebook has over one billion active users, more than half of them using Facebook on a mobile device. Users must register before using the site, after which they may create a personal profile, add other users as friends, and exchange messages, including automatic notifications when they update their profile. Additionally, users may join common-interest user groups, organized by workplace, school or college, or other characteristics, and categorize their friends into lists such as "People From Work" or "Close Friends". Facebook is used for language learning. It facilitates the interaction between the students and the instructors and between the students themselves. The uses of Facebook in language learning were examined by some studies (e.g., Kamarul, Norlida \& Zainol, 2010; Mitchell, 2012).

Kamarul, Norlida and Zainol (2010) investigated if university students consider Facebook as a useful and meaningful learning environment that could support, enhance and strengthen their learning of English. The study found that the students believed Facebook could be utilized as an online environment to facilitate the learning of English. Nevertheless, teachers have to integrate Facebook as an educational project with pre-determined learning objectives and outcomes for the learning experience to be meaningful. Mitchell (2012) explored the students' motivations for joining Facebook. The students in this study joined Facebook for social reasons. Their use over a four-week period and interview data showed that they were able to communicate with existing friends, learn English, and learn about American culture through Facebook. They were able to accomplish their goals on Facebook with few difficulties.

\subsubsection{YouTube}

YouTube is a video-sharing website, created in February 2005, on which users can upload, view and share videos. YouTube is used to display a wide variety of user-generated video content, including movie clips, TV clips, and music videos, as well as amateur content such as video blogging, short original videos, and educational videos. YouTube can be used for language learning purposes. In the literature, some studies were conducted to examine the impact of YouTube in language learning. (e.g. Hafner \& Miller ,2011; Miller, Hafner \& Fun, 2012). 
Miller, Hafner and Fun (2012) presented a new approach to English for Academic Purposes (EAP) course design. Students carried out a simple scientific experiment, documenting procedures, results and interpretation in the form of a digital video uploaded and shared through YouTube. This use of multimodal scientific documentaries as a pedagogical tool in EAP was reported with reference to data drawn from a student questionnaire, interviews with students, and students' comments in a course weblog. The findings showed that the students perceived both linguistic and technical value in the construction and sharing of their multimodal documentaries. Hafner and Miller (2011) created a course which was a student-centered digital video project, in which students created and shared a multimodal scientific documentary. A range of new technologies and Web 2.0 platforms (including YouTube and Edublogs) were integrated into the project process in order to create a technologically rich learning environment. They drew on students' accounts (from questionnaires, focus group interviews, and Weblog comments) to evaluate the digital video project and associated technological environment.

\subsubsection{Wikis}

A wiki is a website which allows its users to add, modify, or delete its content via a web browser usually using a simplified markup language or a rich-text editor. Wikis serve many different purposes, such as knowledge management and note taking. Some wikis permit control over different functions. For example, editing rights may permit changing, adding or removing material. Wikis can be used for language learning. Their implementations in language learning were examined by some studies (e.g., Castaneda, 2011; Mak \& Coniam, 2008; Zorko, 2009).

Castaneda (2011) investigated the differences in levels of achievement between students who used instruction with video/photo blogs and wikis, compared to those who used instruction with traditional text-based technologies. Results revealed that there were no significant differences at the production level between the students who used video/photo blog and wiki technologies vs. those who used traditional technologies. However, significant differences were found at the recognition level for the group that used video/photo blogs and wikis when compared with those who used traditional technologies. General mean results revealed that the groups using video/photo blogs and wikis outperformed those who used traditional technologies. Mak and Coniam (2008) investigated authentic writing through the use of wikis. The wikis were used as a collaborative writing platform to produce wiki content that describes the different facilities and features of their school. The students' final draft became a printed brochure of their "new" school to be distributed to parents. In the light of this real "outcome", the paper discusses the place of authentic writing, situated within the domains of creativity and task-based learning, in a school's ESL programme. The results indicated that two significant impacts wiki could have to improve writing skills. First, the task's real outcome boosted students' confidence as writers. Second, it tapped students' creative skills. Another outcome worthy of note was that of peer review in writing - a novel concept for the students who participated in the project.

Zorko (2009) explored the factors that affect the ways students collaborate in the wiki environment. A qualitative exploration of students' perceptions of collaboration in the wiki was carried out among sociology students at university level who used this environment in blended, problem based learning as part of their "English for Specific Purposes" course. The research showed that the wiki promoted much collaborative behaviour among students, such as learning from each other and communicating with the teacher. However, the data indicated that the wiki was less successful in facilitating other types of collaboration, such as communicating with peers and co-constructing products. Overall, the results obtained here confirmed that the wiki can be used to enhance effective collaboration in a constructivist approach to language learning. Stickler and Hampel (2010) asked two learners to take part in an intensive online course offered to intermediate level students. The course piloted the use of a Moodle-based virtual learning environment and a range of new online tools which lend themselves to different types of language learning activities (e.g., wikis for collaboration and blogs for reflective learning).The study showed that an online language course can combine different approaches to learning and teaching, such as using language communicatively and focusing on form and language practice. Elola and Oskoz (2010) explored L2 learners' approaches to the writing task in the wikis. They also examined learners' collaborative synchronous interactions when discussing content, structure and other aspects related to the elaboration of the writing task. Analysis of the data showed that while statistically significant differences were not evident in terms of fluency, accuracy and complexity when comparing the individual and collaborative assignments, there were observable trends that indicated how learners' interactions with the text differ when working individually or collaboratively. Further, an analysis of learners' approaches to collaborative writing through the use of social tools showed that wikis and chats allowed them to concentrate on writing components in a different, yet complementary, manner depending on whether they interacted in the wikis or in the chats. Lund (2008) found that the wiki held the potential for collective knowledge advancement and language development. Bradley, Lindström and Rystedt (2010) investigated what wikis could do as a means to enhance group interaction, when students were encouraged to participate in constructing text and exchanging peer response. The 
study showed that collaboration became specifically interesting from a language learning perspective. On the student wiki pages there were numerous contributions relating to both local language and global content. Pellet (2012) proposed a social-constructivist model that integrated CMC and collaborative learning to teach two advanced undergraduate L2 content-based courses using a wiki as a medium. The study suggested that the "read-and-write" Internet offers a unique medium for constructive learning approaches, which together can help students develop learner autonomy and metacognitive skills.

\subsubsection{Blogs}

A blog is a discussion or informational site published on the World Wide Web and consisting of discrete entries "posts" typically displayed in reverse chronological order (the most recent post appears first). More recently, multi-author blogs have developed, with posts written by large numbers of authors and professionally edited. Blogs have some benefits to language learning which examined by some studies (e.g. Hsu, Wang \& Comac 2008). They investigated how the use of audio blogs can help to meet an instructor's need to improve instruction in English as a second language (ESL). The instructor used audio blogs to manage oral assignments, to interact with learners, and to evaluate performance outcomes. The results indicated that the use of audio blogs met the instructor's instructional needs, providing an efficient and effective way to evaluate students' oral performance and permitting individualized oral feedback. In addition, learners enjoyed the ease of using audio blogs and believed that audio blogs assist their language-learning experience.

Recently, almost every month a new technology is introduced. This creates challenges for researchers to pretend that one can capture the snap-shot of the area. New technology, new issues, new methods, and new topics are constantly emerging. In this regard, there are many other environments that can be used for language learning. They are not discussed here because here some of them are mentioned as examples. Emails, MSN, Twitter, Flicker, MySpace, and much more are used for communication and can be used for language learning.

Based on the results mentioned above, the study questions can be summarized. The first question of this study addressed the general factors affecting the implementation of CMC in language learning. The studies reviewed here have explored the factors that affect CMC implementation in language learning. Looking back to the previous studies, one can find that they have neglected the ways in which the teachers can integrate these CMC environments and organize suitable tasks. These studies focused on the benefits and factors affecting CMC. The principles of using CMC are not introduced in the literature. Chapelle (2003) pointed out that the profession needs principles that can be applied, studied, and developed. Therefore, further studies are necessary to determine the principles that are required to implement CMC in language learning.

The second question of this study addressed the uses of CMC in teaching language skills. This review shows that some of the previous studies have examined the benefits of CMC in comparison to traditional face-to-face classrooms. These studies have examined the benefits of CMC in teaching language skills (listening, speaking, reading, and writing).

The third question of this study addressed the current CMC environments used for language learning. Examples of CMC environments such as YouTube, wikis, and Facebook were presented by many studies and their use in the field of language learning. However, there are some issues are not fully examined. According to Chapelle (2003) useful researches are those that provide some evidence about the design of the software, the learners' use of CALL, or the way that the teacher has organized the task.

\section{Conclusions and Suggestions for Further Studies}

Studies on CMC have contributed to the body of literature which indicated the benefits of CMC in language learning. These studies have shown how CMC environments can be used to enhance language learning. The factors affecting the use of CMC in language learning were explored by a good number of studies. Current CMC environments were examined to find out how they can be integrated into language teaching and learning. However, the literature paid no attention to some specific topics. This review suggests further studies to investigate how language teachers can integrate CMC environments and organize suitable tasks. Also, further studies are necessary to determine the principles that are required to implement CMC in language learning.

The findings of this review will help language learning researchers to find out the areas that were not examined fully in the literature. However, there are some limitations. The first one concerns the topics discussed in this review. The review has discussed many topics under five major categories, yet some topics were not mentioned. For example, the review did not deal with the theories used to explain the nature of CMC (i.e. cognitive and socio-cultural). The 
second one concerns the period of the studies reviewed. All studies were published between 2000 and 2013. It would be better if no specific period of time was determined. In spite of these limitations, this review hopefully makes a sound contribution to the field of CMC.

In the literature, each environment was examined in isolation in terms of its uses and benefits for language learning.

Therefore, the author of this review suggests that there is a need to examine how can language teachers utilize the CMC environment effectively. The current CMC environments can be compared to find out which ones can be useful for the language learners and can cover all the language skills. In other words, which CMC environment can be used for all language skills? Therefore, this review suggests that future research can be conducted to find out which environment will be more useful for language learning.

\section{Acknowledgments}

The author of this study would like thank the Deanship of Scientific Research, Najran University, Saudi Arabia for granting this research. Grant Number: NU/SHED/13/ 12.

\section{References}

Abraham, L. B. (2008). Computer-mediated glosses in second language reading comprehension and vocabulary learning: A meta-analysis. Computer Assisted Language Learning, 21(3), 199-226. http://dx.doi.org/10.1080/09588220802090246

Absalom, M., \& Rizzi, A. (2008). Comparing the outcomes of online listening versus online text-based tasks in university level Italian L2 study. ReCALL, 20(1), 55-66. http://dx.doi.org/10.1017/S0958344008000517

Alastuey, M. C. B. (2011). Perceived benefits and drawbacks of synchronous voice-based computer-mediated communication in the foreign language classroom. Computer Assisted Language Learning, 24(5), 419- 432. http://dx.doi.org/10.1080/09588221.2011.574639

Barrs, K. (2012). Fostering computer-mediated L2 interaction beyond the classroom. Language Learning \& technology, 16(1), 10-25.

Blake, R. (2000). Computer-mediated communication: A window on L2 Spanish interlanguage. Language Learning \& technology, 4(1), 120-136.

Bradley, L., Lindstro, B., \& Rystedt, H. (2010). Rationalities of collaboration for language learning in a wiki. ReCALL, 22(2), 247-265. http://dx.doi.org/10.1017/S0958344010000108

Brandl, K. (2012). Effects of required and optional exchange tasks in online language learning environments. ReCALL, 24(1), 85-107. http://dx.doi.org/10.1017/S095834401100030

Castaneda, D. A. (2011). The effects of instruction enhanced by video/photo blogs and wikis on learning the distinctions of the Spanish preterite and imperfect. Foreign Language Annals, 44(4), 692-711. http://dx.doi.org/10.1111/j.1944-9720.2011.01157.x

Chapelle, C. A. (2003). English language learning and technology: Lectures on teaching and research in the age of information and communication. Amsterdam: John Benjamins Publishing.

Cole, L., Beam, M., Karn, L., \& Hoad-Reddick, A. (1992). Educational computer-mediated communication. A field study of recent research. Unpublished paper, Toronto, Canada: Ontario Institute for Studies in Education.

Develotte, C., Guichon, N., \& Vincent, C. (2010). The use of the webcam for teaching a foreign language in a desktop videoconferencing environment. ReCALL, 22(3), 293-312.

Elola, I., \& Oskoz, A. (2010). Collaborative writing: Fostering foreign language and writing conventions development. Language Learning \& Technology, 14(3), 51-71. http://ltt.msu.edu/issues/october2010/elolaoskoz.pdf

Freiermuth, M. R. (2001). Native speakers or non-native speakers: Who has the floor? Online and face-to-face interaction in culturally mixed small groups. Computer Assisted Language Learning, 14(2), 169-199. http://dx.doi.org/10.1076/call.14.2.169.5780

Fuente, M. (2003). Is SLA interactionist theory relevant to CALL? A study on the effects of computer-mediated interaction in L2 vocabulary acquisition. Computer Assisted Language Learning, 16(1), 47-81. http://dx.doi.org/10.1076/call.16.1.47.15526 
Godwin-Jones, R. (2005). Skype and podcasting: Disruptive technologies for language learning. Language Learning \&Technology, 9(3), 9-12.

Hafner, C. A., \& Miller, L. (2011). Fostering learner autonomy in English for Science: A collaborative digital video project in a technological learning environment. Language Learning \& Technology, 15(3), 68-86.

Higgins, R. (1991). Computer-mediated cooperative learning: Synchronous and asynchronous communication between students learning nursing diagnosis. Unpublished doctoral dissertation. University of Toronto. Retrieved from http://www.cybercorp.net/rhiggins/thesis/

Hsu, H. Y., Wang, S. K., \& Comac, L. (2008). Using audio blogs to assist English-language learning: an investigation into student perception. Computer Assisted Language Learning, 21(2), 181-198. http://dx.doi.org/10.1080/09588220801943775

Kitade, K. (2000). L2 Learners' discourse and SLA theories in CMC: Collaborative interaction in internet chat. Computer Assisted Language Learning, 13(2), 143-166. http://dx.doi.org/10.1076/0958-8221 (200004)13:2; 1-D; FT143

Ko, C. (2012). Can synchronous computer-mediated communication (CMC) help beginning-level foreign language learners speak? Computer Assisted Language Learning, 25(3), 217-236. http://dx.doi.org/10.1080/09588221.2011.649483

Kotter, M. (2001). MOOrituri te salutant? Language learning through MOO-based synchronous exchanges between learner tandems. Computer Assisted Language Learning, 14(3-4), 289-304. http://dx.doi.org/10.1076/call.14.3.289.5795

Lin, W.-C., Huang, H.-T., \& Liou, H.-C. (2013). The effects of text-based SCMC on SLA: A meta analysis. Language Learning \& Technology, 17(2), 123-142.

Lund, A. (2008). Wikis: a collective approach to language production. ReCALL, 20(1), 35-54. http://dx.doi.org/10.1017/S0958344008000414

Luppicini, R. (2006). Review of computer mediated communication research for education. Instructional Science, 35(2), 141-185. http://dx.doi.org/10.1007/s11251-006-9001-6

Mak, B., \& Coniam, D. (2008). Using wikis to enhance and develop writing skills among secondary school students in Hong Kong. System, 36(3), 437-455. http://dx.doi.org/10.1016/j.system.2008.02.004

Metz, J.M. (1994). Computer-mediated communication: Literature review of a new context. Interpersonal computing and technology: An electronic journal for the 21st century, 2(2), 31-49.

Miller, L., Hafner, C. A., \& Fun, C. N. K. (2012). Project-based learning in a technologically enhanced learning environment for second language learners: Students' perceptions. E-Learning and Digital Media, 9(2), 183-195.

Mitchell, K. (2012). A Social tool: Why and how ESOL students use Facebook. CALICO Journal, 29(3), 471-493.

Murphy, P. (2010). Web-based collaborative reading exercises for learners in remote locations: the effects of computer-mediated feedback and interaction via computer-mediated communication. ReCALL, 22(2), 112-134. http://dx.doi.org/10.1017/S0958344010000030

Nguyen, L. V. (2011). Learners' reflections on and perceptions of computer- mediated communication in a language classroom: A Vietnamese perspective. Australasian Journal of Educational Technology, 27(8), 1413-1436.

O'Bryan, A., \& Hegelheimer, V. (2007). Integrating CALL into the classroom: the role of podcasting in an ESL listening strategies course. ReCALL, 19(2), 162-180. http://dx.doi.org/10.1017/S0958344007000523

Pellet, S. H. (2012). Wikis for building content knowledge in the foreign language classroom. CALICO, $29,2$.

Pellettieri, J. (2000). Negotiation in cyberspace: The role of chatting in the development of grammatical competence. In. M. Warschauer \& R. Kern (Eds.), Network-Based Language Teaching: Concepts and Practice (59-86). Cambridge: Cambridge University Press.

Peterson, M. (2001). MOOs and second language acquisition: Towards a rationale for MOO- based learning. Computer Assisted Language Learning, 14(5), 443-459. http://dx.doi.org/10.1076/call.14.5.443.5773

Peterson, M. (2009). Learner interaction in synchronous CMC: a sociocultural perspective. Computer Assisted Language Learning, 22(4), 303-321. http://dx.doi.org/10.1080/09588220903184690

Robert, G.J. (2005). Emerging technologies Skype and podcasting: disruptive technologies for language learning. 
Language Learning \& Technology, 9(3), 9-12.

Romiszowski A., \& Mason R. (2004). Computer-mediated communication. In: Jonassen D. (eds.), Handbook of Research for Educational Communications and Technology (2nd Ed.). Lawrence Erlbaum, Mahwah NJ, pp. 397-431.

Shamsudin, S., \& Nesi, H. (2006). Computer-mediated communication in English for specific purposes: A case study with computer science students at Universiti Teknologi Malaysia. Computer Assisted Language Learning, 19(4-5), 317-339. http://dx.doi.org/10.1080/09588220601043164

Shang, H. F. (2007). An exploratory study of e-mail environment on FL writing performance. Computer Assisted Language Learning, 20(1), 79-96. http://dx.doi.org/10.1080/09588220601118479

Stickler, U., \& Hampel, R. (2010). CyberDeutsch: Language production and user preferences in a Moodle virtual learning environment. CALICO Journal, 28(1), 49-73.

Suk H., Young, \& Vrongistinos, K. (2012). Using Blackboard and Skype for mentoring beginning teachers. American Journal of Distance Education, 26(3), 172-179. http://dx.doi.org/10.1080/08923647.2012.697019

Sykes, J. M. (2005). Synchronous CMC and pragmatic development: Effects of oral and written chat. CALICO Journal, 22(3), 399-431.

Tu, C. (2002). The Impacts of Text-based CMC on Online Social Presence. The Journal of Interactive Online Learning, 1, 2.

Vurdien, R. (2011). Enhancing writing skills through blogging in an advanced English as a Foreign Language class in Spain. Computer Assisted Language Learning, 1-18. http://dx.doi.org/10.1080/09588221.2011.639784

Wallace, R. (2003). Online learning in higher education: a review of research on interactions among teachers and students. Education, Communication \& Information, 3(2), 241-280. http://dx.doi.org/10.1080/14636310303143

Wang, Y. (2006). Negotiation of meaning in desktop videoconferencing- supported distance language learning. ReCALL, 18(1), 122-146. http://dx.doi.org/10.1017/S0958344006000814

Warschauer, M. (2001). Online communication. In R. Carter \& D. Nunan (Eds.), The Cambridge guide to teaching English to speakers of other languages (207-212). Cambridge: Cambridge University Press.

Weininger, M. J., \& Shield, L. (2003). Promoting oral production in a written channel: An investigation of learner language in MOO. Computer Assisted Language Learning, 16(4), 329-349. http://dx.doi.org/10.1076/call.16.4.329.23414

Xiao, M., \& Yang, X. (2005). The effects of internet-based desktop videoconference on EFL students oral skills in terms of linguistic accuracy, fluency, and complexity. In P. Kommers \& G. Richards (Eds.), Proceedings of world conference on educational multimedia, hypermedia and telecommunications 2005 (pp. 882-885). Chesapeake, VA: AACE.

Yamada, M., \& Akahori, K. (2007). Social presence in synchronous CMC- based language learning: How does it affect the productive performance and consciousness of learning objectives? Computer Assisted Language Learning, 20(1), 37-65. http://dx.doi.org/10.1080/09588220601118503

Yanguas, I. (2010). Oral computer-mediated interaction between L2 learners: It's about time! Language Learning \& Technology, 14(3), 72-93.

Yilmaz, Y (2011). Task Effects on Focus on Form in Synchronous Computer-Mediated Communication. The Modern Language Journal, 95, 115-132. http://dx.doi.org/10.1111/j.1540-4781.2010.01143.x

Yilmaz, Y., \& Granena, G. (2010). The effects of task type in Synchronous Computer- Mediated Communication. ReCALL, 22(1), 20-38. http://dx.doi.org/10.1017/S0958344009990176

Young, S. S. C. (2003). Integrating ICT into second language education in a vocational high school. Journal of Computer Assisted Learning, 19, 447-461.

Zeng, G., \& Takatsuka, S. (2009). Text-based peer-peer collaborative dialogue in a computer-mediated learning environment in the EFL context. System, 37, 434-446. http://dx.doi.org/10.1016/j.system.2009.01.003

Zorko, V. (2009). Factors affecting the way students collaborate in a wiki for English language learning. Australasian Journal of Educational Technology, 25(5), 645-665. 